\title{
ENTRE LO SAGRADO Y LO PROFANO: CHIMPAY COMO “CUNA DE CEFERINO NAMUNCURÁ"
}

\section{- MARÍA JOSÉ JUNQUERA ${ }^{1}$}

1 Licenciada en Geografía y estudiante avanzada del Profesorado en Geografía. Becaria del CONICET (Beca Interna de Finalización de Doctorado). Tema: Territorialidades e identidad religiosa: Ios salesianos en la región de Norpatagonia (Director: Dr. Roberto Bustos Cara. Co-Directora: Dra. María Cecilia Martin). Actualmente participa en Proyectos de Grupos de Investigación dentro de la UNS y en actividades de extensión universitaria y se desempeña como docente de enseñanza media. E-mail de contacto: majo.junquera@gmail.com

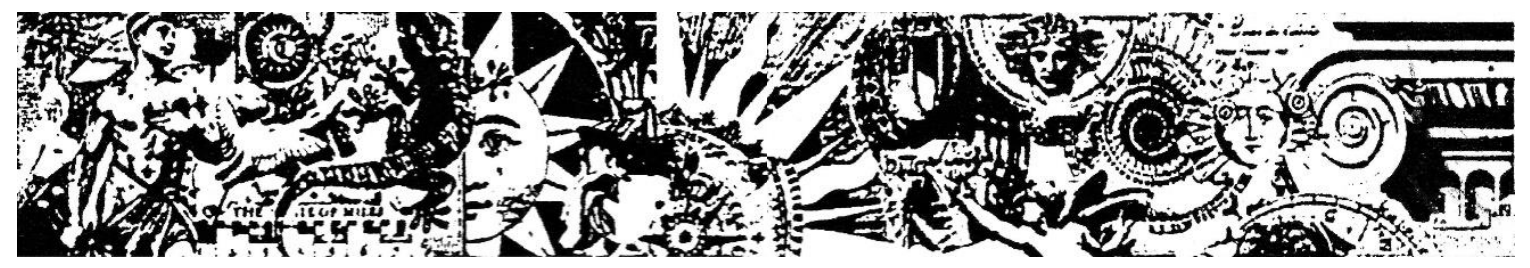

Resumen: Los lugares sagrados se configuran a partir de múltiples formas de territarialidad de las prácticas religiosas de los grupos sociales. Si bien su origen se asocia a un evento o sucesa hierofánico que marca una separación con el entorno profano circundante (ELIADE, 1985), es sabida que su configuración no es ajena al contexto cultural, político y social imperante. Así, los lugares sagrados pueden considerarse territorios porque son el resultado no sólo de una apropiación simbólica o afectiva por parte de los sujetos, sino también porque están atravesados por relaciones de poder y, en consecuencia, pueden devenir en potenciales escenarios de conflicto (RDSENDAHL, 2009). Situanda la mirada desde el abordaje cultural en Geggrafía, nos proponemos comprender a través de un estudio de casa, qué lógicas y qué procesas se entrelazan en la configuración de las lugares sagradas. Se seleccionó la lacalidad de Chimpay, ubicada en la provincia de Rín Negro, Argentina; esta hierópolis es canacida por ser la "tierra" dande nació el beato Ceferina Namuncurá, suceso que la ha convertida en uno de las centros de peregrinación religiosa más importantes de la región patagúnica. Partiendo de la premisa de que las instituciones religiosas son agentes de creación de territarios sagrados que se arganizan y estructuran en función de relaciones jerárquicas de poder (RDSENDAHL, 2005; CARBALLD, 2007), se busca comprender el pracesa de construcción territarial de Chimpay como "Cuna de Ceferino Namuncurá" desde la mirada de das actares saciales: la iglesia católica -congregación salesiana- y el sector pública; así como constatar la presencia de territarialidades en tensión en el pracesa de construcción identitaria de la lacalidad. Desde un enfaque cualitativa de investigación, las 
técnicas de recopilación de infarmación incluyeron entrevistas semiestructuradas y en profundidad a informantes clave, análisis de fuentes documentales y observación participante.

Palabras clave: lugar sagrado; territorialidad; Ceferino Namuncurá; congregación salesiana

\section{BETWEEN THE SACRED AND THE PRDFANE: CHIMPAY AS THE "CRADLE OF CEFERIND NAMLNCLURÁ"}

ABSTRACT: SACRED PLACES ARE CDNFIGURED FROM MULTIPLE FDRMS OF TERRITQRIALITY DF THE RELIGIDUS PRACTICES OF SOCIAL GROUPS. ALTHDUGH ITS QRIGIN IS ASSOCIATED WITH AN HIERDPHANIC EVENT THAT MARKS A SEPARATION FRDM THE

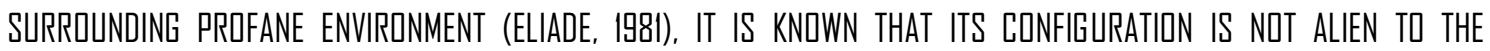
PREVAILING CULTURAL, POLITICAL AND SOCIAL CDNTEXT. THUS, SACRED PLACES CAN BE CONSIDERED TERRITDRIES BECAUSE THEY ARE THE RESULT NOT ONLY OF A SYMBOLIC OR AFFECTIVE APPRDPRIATION IN THE PART OF THE SUBJECTS, BUT ALSD BECAUSE tHEY ARE CRDSSSED BY PDWER RELATIONS AND, CONSEQUENTLY, THEY CAN BECDME PDTENTIAL CDNFLLCT SCENARIIS (RDSENDAHL, 2009). PLACING THE GAZE FRDM THE CULTURAL APPRDACH IN GEOGRAPHY, WE PROPOSE TD UNDERSTAND THRDUGH A CASE STUDY, WHAT LOGICS ARE INTERTWINED IN THE CONFIGURATION OF SACRED PLACES. THE TOWN DF CHIMPAY, LOCATED IN THE PRDVINCE OF RÍ⿴囗口 NEGRD, ARGENTINA, WAS SELECTED; THIS HIERDPOLIS IS KNDWN FOR BEING THE "LAND" WHERE BLESSED CEFERIND NAMUNCURÁ WAS BORN, AN EVENT THAT HAS MADE IT QNE UF THE MDST

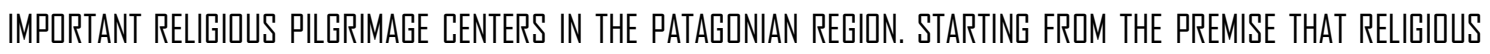
INSTITUTIONS ARE AGENTS OF CREATION OF SACRED TERRITDRIES THAT ARE QRGANIZED AND STRUCTURED ACCORDING TD hiERARCHICAL POWER RELATIONS (RDSENDAHL, 2005; CARBALLU, 2007), IT SEEKS T0 UNDERSTAND THE PRDCESS OF

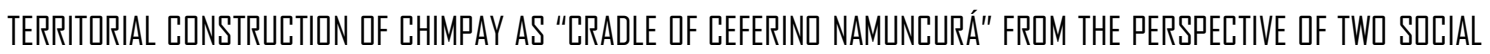
ACTORS: THE CATHOLIC CHURCH -SALESIAN CONGREGATION- AND THE PUBLIC SECTOR; AS WELL AS VERIFYING THE PRESENCE OF TERRITURIALITIES IN TENSION IN THE IDENTITY CONSTRULTION PROCESS OF THE LOCALITY. FRDM A QUALITATIVE RESEARCH APPRDACH, INFORMATION GATHERING TECHNIQUES INCLUDED SEMI-STRUCTURED AND IN-DEPTH INTERVIEWS WITH KEY INFORMANTS, ANALYSIS OF DOCLMENTARY SOURCES, AND PARTICIPANT QBSERVATION.

KEYWDRDS: SACRED PLACE; TERRITDRIALITY; CEFERIND NAMUNCURÁ; SALESIAN CDNGREEGTIIN

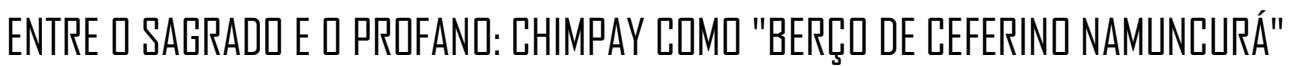

RESUMU: DS LUGARES SAGRADUS SÃ̃ CONFIGURADOS A PARTIR DE MÚLTIPLAS FORMAS DE TERRITDRIALIDADE DAS PRÁTICAS RELIGIOSAS DUS GRUPUS SOCIAIS. EMBDRA SUA DRIGEM ESTEJA ASSOCIADA A UM EVENTO HIERDFÔNICO QUE

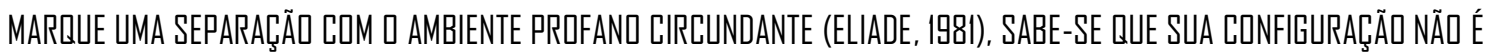

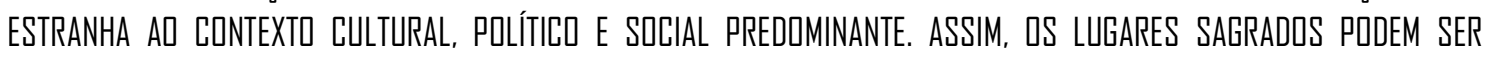

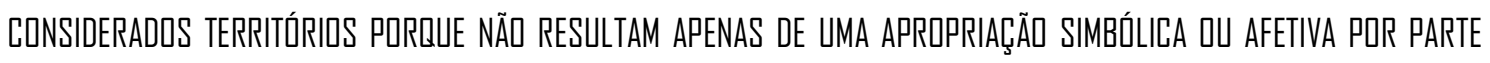

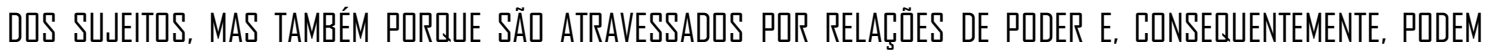
CONVERTER-SE EM PDTENCIAIS CENÁRIIDS DE CDNFLITO (RDSENDAHL, 2009). CDLLCANDO Q OLHAR DESDE A ABDRDAGEM CULTURAL EM GEOGRAFIA, PROPOMDS ENTENDER ATRAVÉS DE UM ESTUDO DE CASD, QUAIS LÓGICAS E QUAIS PRDCESSOS ESTÃ̃ ENTRELAÇADOS NA CONFIGURAÇÃ̃ DOS LUGARES SAGRADOS. A CIDADE DE CHIMPAY, LOCALIZADA NA PRQVÍNCIA DE

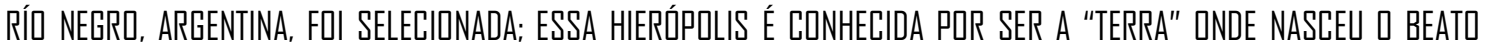
CEFERIND NAMUNCURÁ, UM EVENTO QUE Q TORNDU UM DIS MAIS IMPORTANTES CENTRDS DE PEREGRINAÇÃ̃ RELIIIOSA DA

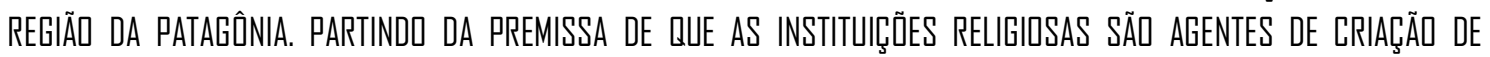

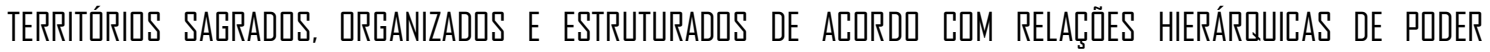

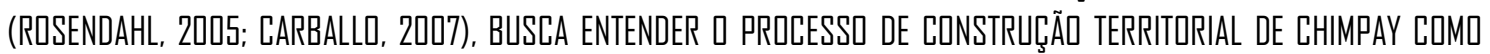

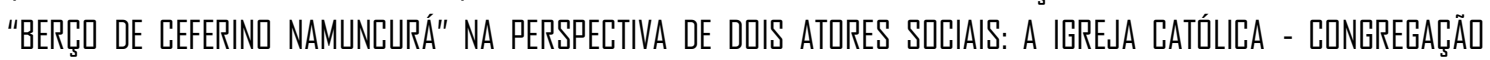

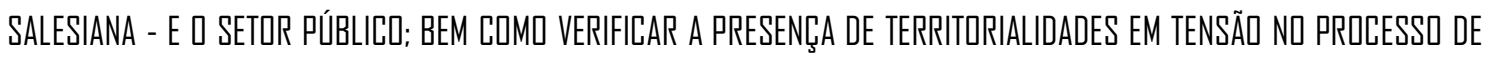


CINSTRUÇ̃̃̃ DA IDENTIDADE DA LOCALIDADE. A PARTIR DE UMA ABDRDAGEM QUALITATIVA DE PESQUISA, AS TÉCNICAS DE COLETA DE INFORMACD̃ES INCLUÍRAM ENTREVISTAS SEMIESTRUTURADAS E APROFUNDADAS COM INFORMANTES-CHAVE, ANÁLISE DE FONTES DOCLMENTAIS E DBSERVAÇ̃̃̃ PARTICIPANTE.

PALAVRAS-CHAVE: LICAL SAGRADD; TERRITQRIALIDADE; CEFERIND NAMUNCURŔ; CLNGREGAÇÃ̃ SALESIANA

\section{Introducción}

La localidad de Chimpay se ubica en el departamento de Avellaneda, provincia de Río Negro, y cuenta con una población de 4.025 habitantes (INDEC, 2010). Comprende -junto a las localidades de Coronel Belisle, Darwin, Choele Choel, Luis Beltrán, Lamarque y Pomona- la región del Valle Medio del río Negro, surcada por el río homónimo. Si bien esta región encuentra en la producción de peras y manzanas su principal sustento económico (TORANZO, 2016), a fines del siglo XX Chimpay se erigió como la "capital espiritual de Río Negro" y uno de los centros de peregrinación religiosa de mayor relevancia en la región patagónica ${ }^{2}$, por ser lugar de nacimiento del beato Ceferino Namuncurá.

La religión es un componente de la cultura y de la identidad de una comunidad, y como tal se imprime en la organización del espacio; se hace visible a través de diversas manifestaciones de fe expresadas de forma material e inmaterial como prácticas, rituales, cultos, objetos y marcas en el paisaje; expresiones que dan cuenta de la relación que se establece entre los miembros de una comunidad, su sistema de creencias y el espacio geográfico (MOUGA POÇAS SANTOS, 2009). Esta relación no está exenta de contradicciones y conflictos ya que se encuentra atravesada por acciones y estrategias que se dan en el marco de relaciones de poder; siguiendo a Fabián Flores, la espacialidad resultante de la apropiación religiosa del espacio “(...) no sólo implica una apropiación material sino también una simbólica y subjetiva empapada de tensiones, conflictos y disputas que operan en torno a relaciones desiguales y complejas" (2016, p. 7).

\footnotetext{
${ }^{2}$ A los fines de este trabajo, se considera como Patagonia a la región argentina comprendida por las provincias de Neuquén, Río Negro, Chubut, Santa Cruz y Tierra del Fuego (INDEC, 2010). Estos territorios tienen un pasado en común asociado a su incorporación al Estado nacional a fines del siglo XIX a través de violentas campañas militares de exterminio de la población indígena (FLORIA Y GARCÍA BELSUNCE, 1993); en ese contexto, sus habitantes fueron objeto de campañas de cristianización forzosa por parte de misioneros occidentales (ALBET I MAS, 2006), entre las que se destaca el proyecto educativo-evangelizador de la congregación salesiana.
} 
En este sentido, analizar el fenómeno religioso y las relaciones entre los grupos sociales y su territorio en Argentina supone, a primera vista, una clara asociación entre Iglesia Católica y Estado; creencia sobre la cual se construyó nuestra identidad nacional -el ser católico como sinónimo del ser argentino - (CARBALLO, 2007). Si bien el mapa religioso es en realidad mucho más complejo y diverso, la Iglesia Católica no deja de ser una institución que puja por el control del territorio en la lucha por la "salvación de las almas"; esto adquiere especial relevancia en un contexto de ruptura del monopolio católico, caracterizado por la "pluralización del campo religioso en general y de las creencias en particular, y de una desregulación institucional de lo religioso, traducida en una menor eficacia de los mandatos institucionalizados a la hora de regular la vida cotidiana de los individuos" (ESQUIVEL Y MALLIMACI, 2016, p. $75)$.

En este marco, situando la mirada desde el enfoque cultural en Geografía, el presente trabajo se propone comprender el proceso de construcción territorial de Chimpay como "Cuna de Ceferino Namuncurá" desde la perspectiva de dos actores sociales: la Iglesia Católica -representada por la congregación de los Salesianos de Don Bosco- y el sector público; asimismo, se busca constatar la presencia de territorialidades en tensión en el proceso de construcción identitaria de la localidad. En función de los objetivos propuestos, se plantearon las siguientes hipótesis de trabajo:

- El proceso de construcción territorial de Chimpay como "Cuna de Ceferino Namuncurá” se llevó a cabo a través de la materialización de proyectos colectivos asociados principalmente a dos actores sociales: la congregación salesiana y el Estado en sus esferas municipal, provincial y nacional-. Este proceso convirtió a la localidad, en un primer momento, en un centro religioso-espiritual o hierópolis (ROSENDAHL, 2009); a lo que se agregó en un segundo momento, su funcionalidad como centro turístico.

- La presencia simultánea de proyectos alternativos o contradictorios (BUSTOS CARA, 1998) en torno a la figura de Ceferino Namuncurá define territorialidades que se articulan o superponen en el proceso de configuración identitaria de la localidad.

La metodología se apoya en un enfoque cualitativo de investigación. Las técnicas de recopilación de información incluyeron entrevistas semiestructuradas y en 
profundidad a informantes clave, análisis de fuentes documentales y observación participante. $^{3}$

\section{Lugares sagrados y territorios religiosos: algunas reflexiones teóricas}

Los estudios culturales actuales en Geografía y la Geografía de las Religiones, en particular, se nutren de las nuevas corrientes filosóficas e ideológicas que surgen a finales de 1960 y principios de 1970 en reacción a la geografía neopositivista y los métodos y enfoques cuantitativos, que conciben al espacio como mero soporte físico de las actividades humanas. La creencia en la supuesta objetividad y cientificidad lograda a través de la aplicación de los métodos de las ciencias naturales a las ciencias sociales, objetivando lo humano (SUNYER MARTIN, 2010), llevó a la aproximación a otras aportaciones epistemológicas que se estaban llevando a cabo en otras áreas de las humanidades y ciencias sociales, redefiniendo el objeto de estudio de la geografía. De esta forma, el espacio pasó a ser considerado como una construcción social atravesada por cuestiones culturales e identitarias que le dan entidad, revalorizando el rol de los sujetos y de la sociedad.

Este acercamiento de la Geografía Humana con otras Ciencias Sociales derivó en el surgimiento de nuevas líneas de investigación que incorporaron la teoría social al análisis geográfico; esto implicó una ruptura con las perspectivas "particionales" del espacio, que lo concebían como un objeto aparte, susceptible de ser estudiado por sí mismo, para comprenderlo como una dimensión de la realidad social espacializada (LINDÓN, 2012). De esta manera, se produjo una "inversión del orden de los factores" (ROCHEFORT en LINDÓN, 2012, p. 216) entre lo espacial y lo social, es decir, lo social se colocó en primer término como requisito indispensable para comprender el espacio. Esto es así porque, como señala Lindón, “...la vida social - y la vida misma en sentido amplio - es eminentemente espacial: para el sujeto anónimo la espacialidad de

\footnotetext{
${ }^{3}$ En relación a las primeras, se entrevistó a vecinos de la comunidad de Chimpay y de localidades aledañas; a miembros de la congregación salesiana que formaron parte o actualmente desempeñan funciones en la diócesis y en la parroquia local; y se recabaron testimonios de las autoridades municipales y provinciales. El análisis de fuentes documentales incluyó la revisión de material proveniente tanto del sector eclesiástico como del sector público, facilitados por personal de la biblioteca de la localidad "Pedro Garro Vidal" y de la oficina del Ente de Turismo. Finalmente, se llevó a cabo la observación participante en eventos como el $1^{\circ}$ Foro de Turismo Religioso (Chimpay, noviembre de 2016); la peregrinación al Parque Santuario Ceferiniano en el marco de la Semana de la Fe (Chimpay, agosto de 2017); y el Primer Encuentro para la creación de una Ruta Ceferiniana (Chimpay, febrero de 2020).
} 


\section{7:}

su vida cotidiana es algo omnipresente, no es posible hacer nada sin involucrar espacialidades en múltiples formas” (2012, p. 218). Esta forma de concebir lo social centra su interés en la figura del sujeto, pero va más allá de eso: le interesan los vínculos que se gestan entre el sujeto y su espacio en tanto sujeto-habitante o actor social territorializado, entendido como un agente activo anclado en diversos territorios, y cuya acción se despliega dejando una huella en el espacio que condicionará a ese mismo actor y a otros, en un proceso permanente de consensos, negociaciones y conflictos.

Es en este marco que los estudios culturales adquieren cada vez mayor importancia, incorporando nuevos temas al análisis geográfico. Así, la religión se transformó en un tema cada vez más abordado, constituyendo un campo emergente dentro de la Geografía Cultural: la Geografía de las Religiones. Siguiendo a Fabián Flores (2018), esta área específica se fue consolidando a partir del abandono de los enfoques meramente descriptivos, pasando de un interés en lo morfológico a miradas que ponen el acento en las prácticas y los sentidos culturales que las religiones imprimen en el espacio. En palabras del autor, "el florecer de esta nueva geografía cultural introdujo el abordaje de lo simbólico en los territorios, los paisajes y los lugares, y entonces la dimensión sagrada del espacio comenzó a ser un tópico cada vez más usual dentro de la geografía humana” (FLORES, 2018, p. 9).

Analizar la dimensión sagrada del espacio desde las prácticas religiosas, nos sitúa ante los conceptos de espacio sagrado y espacio profano introducidos a mediados del siglo pasado por el historiador de las religiones Mircea Eliade, en su conocida obra "Lo sagrado y lo profano" (1985). El autor señala que el espacio sagrado -donde ocurre la hierofanía o acto de manifestación de lo divino- es un espacio cualitativamente diferente que irrumpe en la homogeneidad espacial del entorno circundante; como contraparte, el espacio profano es homogéneo y neutro; allí se despliega la cotidianeidad de la existencia humana. Situando el análisis en la dimensión del tiempo, el autor también hace una distinción entre duración profana y tiempo sagrado: "existen los intervalos de Tiempo sagrado, el tiempo de las fiestas (en su mayoría fiestas periódicas); existe, por otra parte, el Tiempo profano, la duración temporal ordinaria en que se inscriben los actos despojados de significación religiosa” (ELIADE, 1985, p. 44). En la actualidad, desde visiones cercanas a las corrientes posmodernas, se ha pues to en discusión el carácter dicotómico de los espacios sagrados y profanos, entendiendo que no existen espacios sagrados per se, sino que estos son sacralizados a través de la 
práctica social (MOUGA POÇAS SANTOS, 2009; FLORES, 2018). En este sentido, Flores advierte sobre el peligro de caer en la "trampa" de la dicotomía entre espacio sagrado y espacio profano a partir de considerarlos como espacios separados e inconexos: "Las dualidades sagrado/profano y/o religioso/secular comenzaron a erosionarse cuando se advirtió la posibilidad de pensar que esas realidades no están tan separadas como Eliade las había planteado, y que en muchos de los casos existen comunicantes que los relacionan y complementan. Entonces, no sería una cualidad dada sino calificada u otorgada en determinados entornos socio-culturales, ya que las manifestaciones de lo sagrado y lo secular pueden interpretarse a través de referencias culturales, experiencias y narrativas" (2018, p. 10).

Por su parte, tomando los aportes de Lily Kong, Mouga Poças Santos (2009) se centra en la definición de la sacralidad del espacio no desde un evento hierofánico sino a partir de relaciones de poder. Si bien reconoce la utilidad del esquema eliadiano para la comprensión de determinadas situaciones, señala que en la constitución del espacio sagrado afloran las contradicciones y tensiones de la sociedad, que pueden tomar la forma de relaciones de dominación/subordinación, inclusión/exclusión, apropiación/desposesión. Desde una perspectiva de análisis similar, son interesantes los aportes que Rosendahl (2005) realiza en torno a los lugares sagrados y su relación con el territorio y la territorialidad. La geógrafa brasileña se enfoca en ellos desde la noción de "hierocracia" - el gobierno de lo sagrado - que se manifiesta espacialmente en la creación, organización y reestructuración de territorios por parte de las instituciones religiosas, cuya intensidad dependerá de su grado de poder ${ }^{4}$. En este sentido, la territorialidad religiosa es entendida por la autora como el conjunto de prácticas y sus expresiones materiales y simbólicas, desarrolladas por instituciones o grupos con el fin de apropiarse, controlar y/o permanecer en un territorio dado. En el caso del catolicismo oficial, la territorialidad religiosa se despliega a través de la implantación de la fe y la "vigilancia" de los fieles en las diócesis y parroquias (ROSENDAHL, 2005). De esta forma, los lugares sagrados pueden considerarse territorios porque son el resultado no sólo de una apropiación simbólica o afectiva por parte de los sujetos, sino también porque están atravesados por relaciones de poder y,

\footnotetext{
${ }^{4}$ Aquí reconoce dos tipos amplios de territorios: por un lado, el que se materializa en el espacio a través de templos, cementerios, oratorios, caminos recorridos por los peregrinos y otras marcas visibles en el paisaje, a través de las cuales es reconocido y experimentado; por otro lado, el que está estructurado administrativamente en unidades político-espaciales delimitadas y presididas por la autoridad del profesional religioso (ROSENDAHL, 2005). En relación a la Iglesia Católica, en este tipo de territorio se pueden distinguir tres niveles jerárquicos administrativos: la sede oficial del Vaticano, la diócesis y la parroquia.
} 
en consecuencia, pueden devenir en potenciales escenarios de conflicto (ROSENDAHL, 2009).

\section{Ceferino Namuncurá: el “santo” de la Patagonia}

La región patagónica ha sido históricamente una región con fuerte presencia salesiana. Desde su llegada a fines del siglo XIX, la congregación inició un proceso de construcción territorial orientado a la educación, la evangelización y la "civilización" de los pueblos originarios y de los jóvenes más necesitados, de acuerdo con los lineamientos del sistema preventivo de Don Bosco. Impulsado por una serie de visiones y sueños proféticos centrados en los territorios australes del continente americano, Don Bosco había diseñado un proyecto misionero para el espacio patagónico. Dicho proyecto tenía como fin la educación y evangelización de los habitantes originarios y fue sintetizado en el documento "La Patagonia y las Tierras Australes del Continente Americano" (BOSCO, 1986). A partir de la educación y evangelización de los jóvenes y niños pertenecientes a las comunidades originarias, el objetivo buscado era penetrar en la sociedad adulta autóctona y evangelizarla en su totalidad. La formación de un clero integrado por nativos completaría la obra evangelizadora y aseguraría la difusión de los principios del cristianismo en la totalidad del territorio patagónico y su continuidad en el tiempo (VANZINI, 2005). La metodología elegida para su concreción consistió en el establecimiento de colegios, orfanatos e internados para pupilos, que funcionaron como centros con presencia salesiana estable. A su vez, se dividió al territorio patagónico en vicariatos o prefecturas apostólicas -entidades eclesiásticas dependientes directamente de la Santa Sede- con el fin de asegurar la implementación de un sistema de acción coordinado y jerárquico de la tarea educativa y misionera. Al darle una estructura canónica a la iniciativa evangelizadora, la congregación salesiana se aseguraba el control exclusivo de la evangelización patagónica, diferenciándose y a la vez, logrando cierta autonomía de acción respecto a la iglesia local (VANZINI, 2005). Ahora bien, el proyecto salesiano fue contemporáneo a otros proyectos de construcción territorial en la región, como los impulsados por el Estado Nacional, con los que entró en tensión o conflicto por el control de las poblaciones.

La figura de Ceferino Namuncurá es ícono de la compleja relación que desde aquella época se dio entre el Estado Nacional, los pueblos originarios y la congregación salesiana. Hijo del cacique Manuel Namuncurá, nació en Chimpay el 26 de agosto de 
1886. Su padre había sido el último cacique en rendirse frente a las tropas del general Julio Argentino Roca, el 5 de mayo de 1883; había actuado como intermediario de su rendición el misionero salesiano Domingo Milanesio. Los relatos biográficos escritos sobre el joven Namuncurá señalan que la pobreza y las pésimas condiciones de vida en las que quedó su pueblo una vez terminada la "Conquista del Desierto", hicieron que a los diez años decidiera ir a estudiar a Buenos Aires, para regresar y "ser útil a su gente" (ENTRAIGAS, 1970). En un principio, ingresó en los Talleres Nacionales de la Marina, en la localidad de Tigre. Pero no se sintió cómodo allí, por lo que su padre se contactó con el ex presidente Luis Sáenz Peña, quien lo derivó con los padres salesianos. Así, inició sus estudios en el Colegio Pío IX y continuó su carrera religiosa en Viedma, bajo la orientación del salesiano Juan Cagliero, con quien luego viajaría a Italia. Enfermo de tuberculosis, murió en Roma el 11 de mayo de 1905, a la edad de 18 años. Sus restos permanecieron en Roma hasta que en 1924 fueron repatriados desde Italia por orden del presidente Marcelo T. de Alvear y llevados a Fortín Mercedes, en el sur de la provincia de Buenos Aires, donde quedaron a cargo de los padres salesianos. En 1947 se inició el proceso de canonización en Viedma. En 1972 fue declarado "Venerable" por la Santa Sede. Finalmente, el 11 de noviembre de 2007 se llevó a cabo la beatificación de Ceferino Namuncurá en Chimpay, la primera en Argentina. En 2009, por pedido de sus familiares, y luego de una controvertida gestión, sus cenizas fueron trasladadas desde Fortín Mercedes a la localidad neuquina de San Ignacio, distante $60 \mathrm{~km}$ de Junín de los Andes, para quedar bajo el cuidado definitivo de su familia de origen.

\section{La construcción territorial de Chimpay como "Cuna de Ceferino Namuncurá”}

La llegada del cristianismo al continente americano de la mano del colonialismo europeo se dio a través de la imposición de la religión católica desde una mirada eurocéntrica, que consideraba a los pueblos indígenas como inferiores. Albet i Mas (2006) señala que "la supuesta preeminencia de la raza blanca se confundió, voluntariamente, con la preponderancia del cristianismo, de manera que en muchas ocasiones la labor de colonizadores y de misioneros se solapó, mezcló o fue en paralelo” (2006: 223). Una vez alcanzada la independencia de los territorios y, más tarde, durante la etapa de consolidación de los Estados nacionales, este discurso hegemónico se mantuvo intacto; esto explica por qué la territorialidad de la Iglesia Católica está 
íntimamente relacionada con la territorialidad del Estado-Nación, en una relación estrecha entre Estado y religión, entre fe y poder (CARBALLO, 2009).

Partimos de este contexto para analizar el fenómeno religioso y la configuración de espacios sagrados en el estudio de caso seleccionado. La localidad de Chimpay se erige como escenario de encuentros y desencuentros entre la Iglesia Católica y el sector público, lo que da cuenta de la existencia de multiterritorialidades. En este proceso pueden identificarse dos períodos que intentamos esbozar a continuación ${ }^{5}$.

Ceferino Namuncurá y la congregación salesiana: hacia la configuración del lugar sagrado

"Chimpay" es un vocablo mapuche que tiene muchas acepciones, pero las más probables son tres: meandro o recodo del río; vado o paso; lugar donde se aloja (CARTA ORGÁNICA MUNICIPAL DE CHIMPAY, 1994). El paraje es bastante antiguo en la geografía de los pueblos originarios: se han encontrado y se siguen encontrando en la zona vestigios de asentamientos indígenas como picaderos, chenques y lugares de enterramiento (NOCETI, 2007). A fines del siglo XIX arribaron al lugar las tropas del Ejército Expedicionario del Desierto. El 5 de mayo de 1885, el cacique araucano Manuel Namuncurá debió ceder el dominio de las tierras al Estado argentino y Namuncurá fue nombrado coronel del ejército. Para la misma época, los salesianos estaban iniciando el proyecto de evangelización de la Patagonia. El padre Domingo Milanesio era el encargado de realizar las "giras" misioneras por toda la región, desde las ciudades de Carmen de Patagones y Viedma - centros de irradiación de las misiones- a lo largo de los ríos Colorado y Negro y llegando hasta la cordillera (ENTRAIGAS, 1970). Chimpay fue uno de los parajes por donde los salesianos realizaron las llamadas "misiones itinerantes", impartiendo sacramentos y enseñanza religiosa a las comunidades allí establecidas. En el año 1888, en cercanías de ese lugar, se bautizó a Ceferino Namuncurá.

\footnotetext{
${ }^{5}$ Es necesario señalar que la periodización propuesta toma como referencia hechos concretos en la localidad y constituye una aproximación para el abordaje de la realidad compleja; siguiendo a Bustos Cara, una periodización constituye la búsqueda de totalidades explicativas de lo estructural: “...es una esquematización extrema y simplemente ordenadora de hechos mayores. Las fechas son solo indicativas y el conjunto propuesto debe entenderse como un simple paso metodológico en el proceso de modelización" (2002, p. 73).
} 
Ahora bien, ¿cómo fue el proceso por el cual se enaltece su figura hasta convertirse en sujeto de devoción? Según Berdoulay (2011), las relaciones de la identidad con la alteridad son reveladoras de la construcción de lugares por el sujeto y, particularmente, de su concretización narrativa. En efecto, el sujeto construye el lugar por la mediación de relatos que dan sentido a su relación con las personas, con los objetos y con el ambiente. Estos relatos corresponden a (re)descripciones de los elementos de este ambiente, desplegadas según una trama narrativa portadora de sentido (BERDOULAY, 2011). En la misma línea, Capellá y Lois González señalan que el sentido y el sentimiento del lugar (topofilia y topofobia) y la construcción histórica de naciones, regiones o comunidades responde a la selección de ciertos acontecimientos considerados relevantes, y que son mitificados (CAPELLÁ y LOIS GONZÁLEZ, 2002). Por lo tanto, para comprender la relevancia de Ceferino Namuncurá para la localidad de Chimpay, debemos remontarnos a 1911, cuando el Padre Esteban Pagliere, salesiano argentino, propuso la idea de comenzar a investigar sobre la obra de Ceferino entre sus conocidos y personas allegadas a él, para luego plasmarlo en un libro con su historia ${ }^{6}$ Dice el padre salesiano Ricardo Noceti en su libro "La sangre de la Tierra" (2007): "Ya en 1911 el P. Esteban Pagliere tenía la intención de escribir la biografía del joven mapuche y el P. José Vespignani lanzaba un prolijo cuestionario para recoger testimonios. (...) Hubo que esperar varios años para tener la primera biografía de Ceferino, que debemos al P. Luis Pedemonte. Desde entonces, se han sucedido diversas publicaciones, algunas de carácter biográfico y documental, otras de carácter espiritual. El P. Emiliano Aparicio ha registrado alrededor de 60 títulos (sin contar obras en las que, por tratarse de estudios de conjunto, la biografía de Ceferino aparece muy sintéticamente) y puede ser que haya habido también otras ediciones que él no hubiera alcanzado a detectar" (NOCETI, 2007, p. 71-72).

De esta manera, comenzó a construirse un relato en torno a la vida de Ceferino Namuncurá que resaltó sus cualidades personales asociadas al ideal de "santo" de la Iglesia Católica y que lo convirtió, con el tiempo, en el beato más famoso de la Patagonia. Como señala Nicoletti: "Para mostrar el resultado concreto de la labor misionera salesiana y de adoctrinar moralmente a los niños y jóvenes educados por la Congregación, el primer biógrafo de Ceferino, Luiggi Pedemonte, inició en la década

\footnotetext{
${ }^{6}$ La primera biografía de Ceferino Namuncurá fue escrita finalmente por el padre Luis Pedemonte bajo el título "Ceferino Namuncurá. El Lirio de la Patagonia" y se editó aproximadamente entre 1938 y 1940 (SAN MARTÍN, 2009). 


\section{3:}

del '30 la confección de un modelo educativo autóctono (...) en base a recuerdos personales de quienes lo conocieron, los testimonios de compañeros, maestros, directores espirituales, y sus propias cartas recopiladas, continuando la práctica salesiana de educar por medio de modelos virtuosos" (2007, p. 124). De igual forma, Chimpay se convirtió en una tierra sagrada por ser lugar de nacimiento del joven mapuche. El padre salesiano Raúl Entraigas escribe en la biografía "El mancebo de la tierra: Ceferino Namuncurá" (1970): "El rocío de la gracia había descendido sobre Chimpay. (...) En Chimpay, sin que Manuel y Rosario se percataron, había bajado el espíritu de Dios sobre su casa humilde, y había besado en la frente a Ceferino” (ENTRAIGAS, 1970, p.35).

El proceso de construcción de Chimpay a través de la mediación de relatos portadores de sentido en torno a la figura de Ceferino Namuncurá fue acompañado de la construcción de materialidades religiosas que comenzaron a transformar el paisaje de la localidad. Así, en el año 1959 el capitán del ejército argentino Mario Raone, cumpliendo una promesa y con la aprobación de la iglesia, hizo construir una mayólica con una foto de Ceferino tomada en Roma en los últimos años de su vida. La misma se hizo en la estación de ferrocarril y desde entonces fue lugar de visita de los pasajeros que pasaban por Chimpay y también de distintos visitantes que llegaban al pueblo desde diversos lugares. Fue también el lugar de concentración de peregrinos cada 11 de mayo - fecha de su muerte y aniversario de Chimpay - y en la semana del 26 de agosto - fecha de su nacimiento -. Este fue el primer monumento a Ceferino Namuncurá que se construyó en la localidad y, según el testimonio de un sacerdote salesiano, el segundo en la región, en torno al cual comenzó a congregarse la comunidad de creyentes.

A partir de la década de 1960 comienza a haber cierta participación del sector público en la configuración de Chimpay como "Cuna de Ceferino". Esta participación siempre estuvo mediada por la Iglesia Católica, en el marco de acuerdos y acciones conjuntas en torno a la organización de eventos y a la construcción de materialidades religiosas que fueron dando una nueva fisonomía al paisaje de la localidad. En este sentido, el 10 de septiembre de 1967 se creó el Santuario y Parque Ceferino Namuncurá, un espacio de descanso, recreación y congregación de fieles creado en honor al beato, que se extiende por una superficie de cuatro hectáreas. El lugar comprende un amplio espacio parquizado, arbolado e iluminado en el que se hallan múltiples elementos - estatuas, templos, placas - que conservan la memoria de 


\section{4:}

Ceferino. El terreno donde se localiza el parque fue donado por una de las familias fundadoras del pueblo a la congregación salesiana; un tiempo después, los salesianos cedieron una parte del mismo al municipio para su gestión, con una clara demarcación de los usos a los que debía ser destinada cada porción del espacio: "Cuando yo estaba, hicimos como un pacto con la municipalidad, un arreglo, y lo dividimos [al terreno] por el medio. En el medio hay una acequia de agua donde plantamos crataegus y se dividió, dijimos va a ser todo espiritual, y una mitad, no sé cuántas hectáreas son, es para la municipalidad pero con la condición de que siempre que la iglesia pidiera el salón multiusos lo pudiéramos usar. Por eso cada vez que queremos hacer algún evento, lo pedimos a la municipalidad, y la municipalidad dispone para que lo usemos con toda tranquilidad. Porque a ellos les dejamos la parte económica de la gente que viene, y nosotros usamos únicamente las ganancias de la santería y lo que hay allí que es una alcancía en el parque” (M.D., sacerdote salesiano).

En 1970 el gobierno provincial estableció por decreto que se celebraría el aniversario de Chimpay el 11 de mayo de 1905, en correspondencia con el día del fallecimiento de Ceferino Namuncurá. El 27 de junio de 1971 el gobierno provincial inauguró el primer monumento a Ceferino Namuncurá en el parque que lleva su nombre y se colocó una escultura hecha en madera de lenga. Es, desde entonces, la imagen más venerada y es allí donde a través de una Comisión Ceferiniana se comenzó a concentrar gran cantidad de visitantes y a realizar distintos actos en homenaje al "Lirio de la Patagonia"7. Nuevamente, este proceso estuvo mediado tanto por la Iglesia Católica como por el sector público: "El parque ceferiniano comenzó a pleno cuando se hizo el monumento. Antes se iba a ese lugar o a la estación, se puso un monumento que al principio era un busto de bronce que lo llevaron a la escuela que hay en Chimpay que se llama Ceferino Namuncurá, (...) y después hicimos uno de madera lenga de cuerpo entero que pareciera casi al natural la figura, que se saca y la gente va, lo abraza, lo besa, le reza cuando hay sobre todo peregrinaciones” (M.D., sacerdote salesiano).

\footnotetext{
7 La metáfora del "Lirio de la Patagonia" es construida por los salesianos a través de los relatos biográficos de Ceferino Namuncurá. La comparación con la flor del lirio, "blanca y delicada, es sinónimo de pureza y virginidad según como lo entendían los salesianos" (SAN MARTíN, 2009, p. 47). Según Nicoletti y Penhos, esta representación se corresponde con el modelo histórico de "santito criollo" que invisibilizó sus orígenes, poniendo en evidencia la tensión permanente entre aboriginalidad y santidad: "la metáfora 'lirio de la Patagonia' expresa poéticamente la necesidad de incorporar, en una clave positiva, los orígenes innegables de Ceferino. Estos aparecen referidos a la región en que nació y se crió en sus primeros años, y no al nombre del sitio preciso, que hubiera seguido una tradición de las advocaciones religiosas (...) Se instala un binomio ideológico y estético que opone blancura-belleza-bondad a negrura-fealdad-maldad, y que es central en el discurso visual religioso" (2010, p. 18).
} 


\section{5:}

Para la misma época, en la década del setenta, empezó a realizarse la Semana de la Fe, hoy la celebración religiosa más multitudinaria ${ }^{8}$ de la Patagonia, que se lleva a cabo anualmente para la fecha del nacimiento de Ceferino Namuncurá y que culmina con una procesión en honor al beato. Esta fiesta, organizada por la diócesis de Viedma y la congregación salesiana contó desde los inicios con una importante participación estatal: "En 1974 se hizo la primera gran fiesta en honor a Ceferino Namuncurá. Fue la primera vez que fue tanta gente, allí el gobernador hizo una gran fiesta e hizo el monumento que hay actualmente. Hicieron una enorme cantidad de asado para la gente y calculan que en ese momento se habían juntado cuatro mil personas" (M.D., sacerdote salesiano).

Fue a partir de 1986 - año aniversario del centenario del nacimiento de Ceferino Namuncurá - cuando la celebración religiosa se convirtió en un fenómeno multitudinario que convocó a varios miles de personas, lo que constituyó una “explosión” - según el testimonio de un sacerdote que en ese momento era párroco de la localidad -. Este hito en la historia de la localidad puede considerarse como el acontecimiento fundante de Chimpay como "Cuna de Ceferino". A partir de entonces, las acciones concertadas entre el municipio, la congregación salesiana y la comunidad de vecinos para la organización de la fiesta se intensificaron. Este proceso no fue ajeno, sin embargo, a ciertos conflictos en torno a los usos del espacio destinado a la celebración, lo que da cuenta de una tensión permanente entre las territorialidades eclesiástica y estatal.

\section{Lo religioso y lo turístico: Ceferino Namuncurá en la encrucijada}

A partir de los años noventa se observa una clara intencionalidad desde las distintas esferas del Estado -a nivel local y provincial- de consolidar a Chimpay como destino de turismo religioso de relevancia a nivel nacional. En efecto, la Carta Orgánica Municipal de Chimpay, sancionada el 30 de noviembre de 1994, menciona en

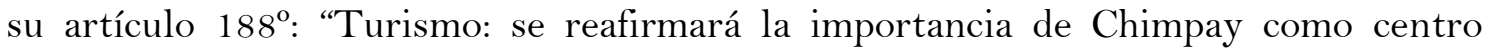
turístico, consolidando un futuro afianzado en dicha actividad. El municipio proporcionará sus recursos turísticos en su territorio con la participación de la

\footnotetext{
${ }^{8}$ Se estima que durante la Semana de Fe ingresan a Chimpay entre 50.000 (cincuenta mil) y 70.000 (setenta mil) personas (Declaración de Chimpay como Capital Provincial del Peregrino, 2018).
} 


\section{6:}

comunidad coordinadamente con Provincia y Nación, identificando a la comunidad como "Cuna de Ceferino" (1994, p. 31).

Asimismo, la Carta Orgánica propone en uno de sus artículos la creación de Entes para el Desarrollo. Esto dio lugar a la creación del Ente Turístico Municipal, por Resolución del Ejecutivo Municipal en el año 2016. Según las palabras del director del Ente, el objetivo prioritario de su trabajo es lograr que Chimpay se vaya transformando paulatinamente en un destino turístico, particularmente religioso, en torno a la figura consagrada de Ceferino Namuncurá. En este sentido, se han ido llevando a cabo múltiples acciones para visibilizar a la localidad, entre las que se pueden mencionar:

- $1^{\circ}$ Foro de Turismo Religioso realizado en Chimpay los días 17 y 18 de noviembre de 2016. Este fue organizado por la Asociación FUNDAMERICA (Fundación Americana para la Promoción del Desarrollo Sustentable y el Turismo), el Ministerio de Cultura, Turismo y Deporte de Río Negro, la Legislatura de Río Negro y la municipalidad de Chimpay; y tuvo el objetivo de reunir a los actores (expertos, eclesiásticos, funcionarios, empresarios y prestadores de servicios) relacionados con turismo religioso en un espacio donde se pudieran debatir y proponer políticas y estrategias para contribuir a la consolidación y al desarrollo de Chimpay como destino de relevancia a nivel regional y nacional.

- Proyecto para declarar a Chimpay como Capital del Peregrino: desde el municipio se ha trabajado para potenciar el turismo religioso y en este sentido se instauró el Festival del Peregrino que tiene lugar cada año a finales de septiembre. Para dicho festival se ingresó a la Legislatura un proyecto para la declaración de interés, social, cultural y turístico. Además se ingresó a la Legislatura un expediente, iniciado el día 11 de octubre de 2018, para declarar a Chimpay como Capital del Peregrino.

- Organización de la $1^{\circ}$ Peregrinación Náutica", uniendo los puntos del río Negro donde transitó su vida Ceferino Namuncurá.

- Proyecto interprovincial para la creación de la "Senda Ceferiniana: Un producto Multidestino”, entre las provincias de Neuquén, Río Negro y Buenos Aires. 


\section{7:}

El creciente interés público, particularmente desde el municipio, en la transformación de Chimpay en un destino turístico religioso en torno a la figura de Ceferino es un proceso atravesado por tensiones y negociaciones permanentes con la iglesia local (parroquia) y regional (diócesis de Viedma). Esto se manifiesta principalmente en la necesidad de concertación sobre los usos del espacio destinados a la celebración. Así, el Parque Santuario a Ceferino se transforma en un espacio en disputa donde entran en juego las territorialidades y las lógicas de ambos actores. Esto demuestra que, si bien desde los dos lados hay un interés mutuo en trabajar coordinadamente, no deja de haber divergencias en el sentido que se le otorga a Ceferino Namuncurá, tensión que se plasma o se materializa en la necesidad de demarcar límites que separen ambas lógicas - la religiosa/espiritual y la profana/turística -. Así lo manifiesta un sacerdote de la parroquia local: "Tuvimos nuestros momentos de tirantez sobre todo cuando yo me puse muy firme... hubo un momento que con el intendente lo fui a ver e hice un arreglo porque habían puesto demasiado cerca una calesita pero no solo chiquita sino una grande, que llevaba a la gente en el aire, dando vueltas, y otras cosas más y la música, todo eso, que estaba relativamente cerca y yo luché mucho porque para poder organizar lo de Chimpay yo recurrí a todos los santuarios del mundo, conseguí un librito donde explicaba cómo era cada santuario, por ejemplo el que más me gustó es el de Lourdes que tiene la población a dos o tres kilómetros de distancia, entonces que también haya una separación entre los que vendían cosas, etc., que al principio era todo ahí adentro, se armaba mucho lío, y se fue consiguiendo lentamente a través de la municipalidad que se organizara, por ejemplo ahora se organiza todo dentro el pueblo, que queda medio... bueno queda a 400 metros nada más, pero ya es una separación. O sea que lo espiritual esté en su propio campo y lo otro, la venta de productos, de cosas, de los vendedores ambulantes, fuera en otro lugar" (M.D., sacerdote salesiano).

Lo anterior evidencia que para el sector público, Ceferino Namuncurá es un producto turístico, una ventaja competitiva que completaría - junto con la Fiesta de la Cereza - la oferta turística de localidad. Esto, en el marco de un proceso iniciado en una década - los años noventa - caracterizada por un estado municipal cada vez más activo en la generación de estrategias de desarrollo local (SILI, 2018). Como contraparte, la Iglesia Católica concibe a Ceferino como el "caso exitoso" de la evangelización de los salesianos en la Patagonia y, desde hace unos años, en un contexto de cambio de paradigma, como el punto de unión y de reencuentro con los 


\section{8:}

pueblos originarios. Si bien la evangelización sigue siendo el eje del proyecto misionero, en el contexto actual de quiebre de las identidades y de declive de la regulación institucional de lo religioso (ESQUIVEL y MALLIMACI, 2016), la congregación salesiana pasa a ser un actor más entre la diversidad de actores locales; esta pérdida de protagonismo implica la necesidad de establecer consensos para reencauzar la cuestión devocional.

\section{Reflexiones finales}

A partir del caso analizado, podemos concluir que la relación entre la Iglesia Católica y el Estado en cada momento ha definido el proceso de construcción territorial de Chimpay como "Cuna de Ceferino Namuncurá"; en este proceso pueden esbozarse dos momentos: un primer momento cuyo protagonista fue la congregación salesiana (Iglesia Católica) asociado a un proyecto educativo-evangelizador con una clara impronta religiosa; y un segundo momento en el que se instala un creciente interés desde el sector público (municipio y gobernación de la provincia) para la transformación de la localidad en un destino de turismo religioso. Sin embargo, es necesario señalar que ambos momentos - y su correlato espacial - no son excluyentes; si bien la definición de cortes en el tiempo se hace necesaria para simplificar la interpretación de la realidad, el paso de un momento a otro es más bien gradual y, lejos de significar la desterritorialización de la Iglesia Católica, se expresa bajo nuevas formas de territorialidades superpuestas. Lo anterior enfatiza la dimensión política de lo religioso (ROSENDAHL, 2005): así como Chimpay se configura como hierópolis, esto no es ajeno sino que es paralelo al interés del Estado en posicionar a la localidad como centro turístico.

La relación oscilante entre el conflicto y la cooperación por parte de ambos actores da cuenta de la existencia de territorialidades en tensión: la eclesiástica y la estatal. Estas territorialidades manifiestan, a su vez, el cruce entre dos sistemas: el sagrado y el profano. Ambos se expresan mediante lógicas que por momentos, coexisten - intereses convergentes entre los actores, que se expresan en discursos conciliadores, acuerdos y acciones conjuntas - y por momentos, se excluyen - intereses divergentes o contradictorios, demarcación de límites, conflictos -. Expresiones como "demasiado cerca”, "que haya una separación”, en palabras de los miembros de la parroquia local entrevistados, son una clara muestra de las estrategias desplegadas - 
principalmente por la Iglesia Católica- para delimitar los usos asignados a cada espacio y no perder el sentido religioso en un contexto de creciente fragmentación del monopolio católico (MALLIMACI y GIMÉNEZ, 2007).

Más allá de esto, es evidente que tanto el Estado como la Iglesia Católica hoy siguen liderando el proyecto territorial "hegemónico" de la localidad: Chimpay como "Cuna de Ceferino Namuncurá". La construcción de un relato que erige a Chimpay como tierra sagrada, tanto desde la esfera eclesiástica como desde la estatal ${ }^{9}$, es el fundamento que justifica y da sentido al proyecto territorial actual. La congregación salesiana y el Estado no dejan de ser los actores que delinean la imagen de Chimpay en torno a Ceferino Namuncurá- en contraposición a un mosaico cultural y religioso mucho más diverso: según el testimonio de algunos vecinos entrevistados, menos del cincuenta por ciento de la población de Chimpay es devota de Ceferino Namuncurá; un porcentaje aún menor lo constituye la comunidad de religión católica practicante. Así, Ceferino aparece como un símbolo religioso que, siguiendo a CLAVAL (2011), mantiene unida a la localidad, proyectando una imagen común, homogénea, pero ocultando la diversidad real.

Por lo tanto, creemos pertinente pensar a Ceferino Namuncurá como el ícono de una lucha de poder, de control de espacios: esa lucha se manifiesta en el complejo proceso de definición de la identidad territorial de la localidad. Cabe preguntarse quedará pendiente para próximas investigaciones - qué otras identidades y qué otros territorios se ocultan detrás de Chimpay como "Cuna del Santo de la Patagonia”.

\footnotetext{
${ }^{9} \mathrm{Al}$ respecto, cabe mencionar las palabras del vicegobernador de la provincia de Río Negro durante el cierre del $1^{\circ}$ Foro de Turismo Religioso realizado en la localidad en el año 2016: “... hay un solo lugar en todo Río Negro que ha sido bendecido por Dios y es este lugar, donde nació el rionegrino más importante con el que contamos, que es un santo del pueblo y seguramente el Papa lo hará santo cuando corresponda (...). Entonces, si este es el lugar que Dios bendijo para que naciera el rionegrino más importante, ¿cómo no poner en valor todo esto? Porque el propio Ceferino por lo que nos decía el Padre Obispo recién, nos está diciendo eso: tenemos que ser útiles a la comunidad y la forma de ser útiles, nos diría tal vez Ceferino hoy, es que aprovechemos esto que Dios hizo aquí que fue bendecir esta tierra. Por eso yo me [traje] un poquito de tierra de acá y sueño con que esta tierra, que es la tierra de Chimpay, que es la tierra de Ceferino, la podamos estar ofreciendo a cada visitante que pase por este lugar y se lleve un poquito de esta tierra, que es una tierra sagrada".
} 


\section{REFERENCIAS BIBLIOGRÁFICAS}

ALBET i MAS, Abel. De cómo la fe mueve montañas... y la religión las convierte en paisaje: una aproximación a la geografía de la religión. En NOGUÉ, Joan y ROMERO, Joan. Las otras geografias. Valencia: Tirant Lo Blanch, 2006, pp. $211-231$.

BERDOULAY, Vincent. El lugar y el espacio público. En: ZUSMAN, Perla; HAESBAERT, Rogerio; CASTRO, Hortensia y ADAMO, Susana (2011.) Geografías culturales. Aproximaciones, intersecciones y desafíos. Buenos Aires: Editorial de la Facultad de Filosofía y Letras de la UBA, 2011.

BOSCO, Juan. La Patagonia y las Tierras Australes del Continente Americano. Bahía Blanca: Editorial del Sur, 1996.

BUSTOS CARA, Roberto. Espacio-tiempo y territorio. En: CERNADAS DE BULNES, Mabel y BUSTOS CARA, Roberto. Estudios Regionales Interdisciplinarios. Bahía Blanca: EdiUNS, 1998.

BUSTOS CARA, Roberto. Los sistemas territoriales: los procesos de estructuración y desestructuración en Argentina. En: Anales de Geografia de la Universidad Complutense. Madrid, v.22, 2002, pp. 113-129.

CAPELLÁ, Hugo y LOIS GONZÁLEZ, Ruben. Geografía cultural: la gran desconocida. En: Boletín de la A.G.E. Madrid, nº34, 2002, pp. 11-18.

CARBAllo, Cristina. Más allá de las creencias... Hacia una interpretación espacial de la distribución y diversidad de cultos en la Argentina. En: CARBALLO, Cristina. Diversidad cultural, creencias y espacio. Referencias empíricas. Luján: Universidad Nacional de Luján, 2007.

CLAVAL, Paul. ¿Geografía Cultural o abordaje cultural en Geografía? En: ZUSMAN, Perla; HAESBAERT, Rogerio; CASTRO, Hortensia y ADAMO, Susana (2011.) Geografías culturales. Aproximaciones, intersecciones y desafios. Buenos Aires: Editorial de la Facultad de Filosofía y Letras de la UBA, 2011.

ELIADE, Mircea. Lo sagrado y lo profano. Madrid: Guadarrama/Punto Omega, 1985.

ENTRAIGAS, Raúl. El mancebo de la tierra: Ceferino Namuncurá. Buenos Aires: Instituto Salesiano, 1970.

ESQUIVEL, Juan Cruz y MALLIMACI, Fortunato. Religión, medioambiente y desarrollo sustentable: la integralidad en la cosmología católica. En: Revista de Estudios Sociales. Bogotá, $\mathrm{n}^{\circ} 60,2016$, pp. 72-86.

FLORES, Fabián. Espacialidad y religiosidad: encuentros y desencuentros teóricometodológicos. En: Revista Cultura y Religión, Vol. X, Nº 1, 2016, pp. 3-16.

FLORES, Fabián. Lo religioso y el espacio. Apuntes desde la Geografía. En: História das religiões em perspectiva: desafios conceituais, diálogos interdisciplinares e questões metodológicas. Curitiba: Editora Prismas, 2018, pp. 1 - 20.

FLORIA, Carlos y GARCÍA BELSUNCE, César. Historia de los argentinos. Buenos Aires: Ediciones Larousse, 1995

INDEC. Censo Nacional de Población, Hogares y Viviendas. Argentina, 2010.

LINDÓN, Alicia. Revisitando lo social de la metáfora dimensional en Geografía. En: SANTARELLI, Silvia y CAMPOS, Marta (2012). Territorios culturales y prácticas religiosas: nuevos escenarios en América Latina. Bahía Blanca: EdiUNS, 2012, pp. 215-242. 
MALLIMACI, Fortunato. y GIMÉNEZ, Verónica. Creencias e increencia en el Cono Sur de América. Entre la religiosidad difusa, la pluralización del campo religioso y las relaciones con lo público y lo político. En: Revista Argentina de Sociología. Buenos Aires, vol. 5, núm. 9, 2007, pp. 44-63.

MOUGA POÇAS SANTOS, Maria da Graça. Religión y dinámica espacial. Del espacio y de los lugares sagrados al territorio religioso. En: CARBALLO, Cristina. Culturas, territorios y prácticas religiosas. Buenos Aires: Prometeo Libros, 2009.

NICOLETTI, María Andrea. Ceferino Namuncurá: un indígena "virtuoso". En: RUNA. Buenos Aires, Vol. 27, $\mathrm{N}^{\circ}$ 1, 2007, pp. 121-145.

NICOLETTI, María Andrea y PENHOS, Marta. Algo más que una estampita: tensiones entre aboriginalidad y santidad en las imágenes de Ceferino Namuncurá. En: Quinto Sol. Santa Rosa, $\mathrm{n}^{\circ} 14,2010$, pp. 11-46.

NOCETI, Ricardo. La sangre de la tierra. Para una nueva visión de Ceferino Namuncurá. Bahía Blanca: Revista Ceferino Misionero, 2007.

ROSENDAHL, Zeny. Hierópolis y procesiones: lo sagrado y el espacio. En: CARBALLO, Cristina. Culturas, territorios y prácticas religiosas. Buenos Aires: Prometeo Libros, 2009.

ROSENDAHL, Zeny. Território e territorialidade: uma perspectiva geográfica para o estudo da religião. En: Anais do X Encontro de Geógrafos da América Latina. São Paulo, 2005.

SAN MARTIN, Celina. La representación salesiana de la vida de Ceferino Namuncurá: controversias a partir de una perspectiva histórica-etnográfica. Tesis de licenciatura. Universidad de Buenos Aires, Facultad de Filosofía y Letras, 2009.

SILI, Marcelo. La acción territorial. Una propuesta conceptual y metodológica para su análisis. En: Rev. Bras. Estud. Urbanos Reg. São Paulo, v.20, n.1, 2018, p.11-31.

SUNYER MARTÍN, Pedro. La geografía histórica y las nuevas tendencias de la geografía humana. En: Lindón, Alicia y Hiernaux, Daniel. Los giros de la Geografía Humana. Desafíos y Horizontes. Barcelona: Anthropos, 2010, pp. 143-174.

TORANZO, Jorge. Producción mundial de manzanas y peras. Allen Río Negro: Ediciones INTA, 2016.

VANZINI, Marcos. El plan evangelizador de Don Bosco según "Las memorias de las misiones de la Patagonia, desde el año 1887 a 1917" del R. P. Bernardo Vacchina, SDB. Bahía Blanca: Sapienza Industria Gráfica., 2005.

\section{Fuentes de información primarias}

- Documento de la Declaración de Chimpay como Capital Patagónica del Peregrino (2019)

- Carta Orgánica Municipal de Chimpay (1994) 